Chapter 31

\title{
Cell Therapy and Muscle Regeneration: Skeletal Myogenic Differentiation of Urine-Derived Stem Cells for Potential Use in Treatment of Urinary Incontinence
}

\author{
Yingai Shi, YuLin Li, JinYu Liu and Yuanyuan Zhang \\ Additional information is available at the end of the chapter
}

http://dx.doi.org/10.5772/55961

\section{Introduction}

Stress urinary incontinence (SUI) is the prevalent form of urinary tract infection [1], affecting nearly 34 million women in the US [2,3]. In men undergoing prostatectomy, postoperative removal of the catheter leads to urine leakage due to SUI in $50 \%$ of cases [4]. The costs of medicine and health care related to SUI are estimated to be $\$ 26$ billion US dollars annually [5]. Damage to the sphincter muscle around the middle segment of urethra and its connective tissue and nerves is a major cause of SUI [6]. The urethra consists of proximal, middle, and distal segments. The midurethra is a critical component in the urethral sphincter complex, which mainly consists of the inner smooth muscle and outer striated muscles. The striated muscle contributes the most to the complex. Urethral striated muscle is significantly reduced with increasing age. Thus, in patients with SUI, when the lost striated muscle can be restored, amelioration of SUI can be expected. Otherwise, the smooth muscle plays a lesser role, but it is still a desirable treatment target to recover sphincter function [7]. Strategies to replace skeletal muscle cells with stem cell therapy could be used in treatment of SUI.

\section{Cell therapy for USI}

Pharmaceutical treatment of SUI has not been successful [8]; in addition, periurethral injection of bulking agents has poor long-term efficacy and is associated with complications such as voiding dysfunction, abscess formation, and pulmonary embolism [9]. Several surgical procedures such as urethral sling surgery or installation of an artificial sphincter have been used to treat patients with SUI over last three decades [10]. Although these procedures can 
reinforce weak muscle tissue at the pelvic floor or around the urethra, deficient urethral sphincter function remains. Furthermore, surgery for SUI sometimes causes complications such as infection and postoperative voiding difficulty [11]. Autologous adult stem cell injection therapy for SUI has recently provided a promising alternative for sphincter tissue regeneration for repair of SUI. Stem cells obtained from skeletal muscle [12], bone marrow [13-15], umbilical cord [16], adipose tissue [17], and more recently, induced pluripotent cells [18] are regarded as possible candidates for use in this therapy. However, harvesting these types of cells is invasive and may cause complications. Furthermore, the amount of tissue that can be safely harvested in some patients, such as skeletal muscle-derived progenitor cells or bone marrow stem cells (BMSCs) in older individuals, limits clinical applications [19]. Thus, an autologous stem cell source that can be obtained using non invasive techniques would be desirable.

Mesechymal stem cells (MSCs) are often used as a cell source for cell therapy in two ways. First, stem cells are implanted directly into the tissues where repair is needed. By secreting paracrine factors, MSCs promote angiogenesis, decrease fibrosis, and recruit stem cells from native tissues to complete the repair, replacement, and regeneration processes at the injured sites. In addition, the surrounding normal cell- and tissue-based signals from the host environment guide the undifferentiated stem cells to give rise to the specific target cells required for tissue regeneration [20]. Second, stem cells are induced to differentiate into the target cells or tissue-like cells in vitro. The induced cells are then implanted into defective sites where normal cells and tissues are not available.

In clinical settings, most patients with SUI acquire chronic injuries related to urethral dysfunction spanning years or even decades. In cases with extensive injuries and fibroblast formation, it would be better to induce the stem cells to differentiate into a myogenic lineage before injection, since the unhealthy or diseased environment (e.g. muscular dystrophy) may not be able to provide efficient differentiation cues required for efficient stem cells differentiation. Therefore, our strategy is to guide USCs to give rise to myogenic differentiation and then lead to repairing the deficiency, and also determine whether USCs can secrete paracrine factors to recruit the resident cells from the host to participate in tissue repair.

\section{Stem cell properties of urine-derived cells}

Tissue-specific stem cells are rare in each tissue or organ. These cells play an important role in replacing aged, injured, and diseased cells and promoting tissue regeneration. However, it is a challenge to isolate these cells for therapeutic purposes. Recently, we successfully established a primary culture system to isolate and repopulate stem cells from regular voided human urine [21]. These cells possess stem cell properties, such as robust proliferation potential and multipotential differentiation capabilities, and are termed urine-derived stem cells (USCs) [22] (Fig.1). USCs expressed a whole set of MSC/pericyte markers and some key cell surface markers, such as CD 105, CD 90, CD 73, and CD 146, but not hematopoietic stem cell makers such as CD 31 and CD34 [21, 23](Fig.2). These cells maintain high telomerase activity and a normal karyotype in culture medium, even after several passages. The cells can differentiate 
into mesodermal cell lineages, such as osteocytes, chondrocytes, adipocytes, and myocytes, including smooth muscle cell differentiation and endodermal lineages (e.g. endothelial and urothelial cells) $[23,24]$. Additionally, USCs can be isolated and cultured from almost every urine sample. Our recent data demonstrate that $100 \mathrm{ml}$ of urine contains about 3-10 USC clones [23]. On average, 12 USC clones can be isolated from one urine sample (about $200 \mathrm{ml}$ ). To induce stem cells to differentiate into skeletal muscle cells more efficiently, cells at the early passage are recommended. Usually, it takes 4 weeks for one cell clone to generate $3.2 \times 10^{7}$ cells at an early passage (p4) [24]. Therefore, at least $4 \times 10^{8}$ USCs $\left(12 \times 3.2 \times 10^{7}\right.$ cells) can be generated from one urine sample, which are enough cells for use in the treatment of any grade of SUI.
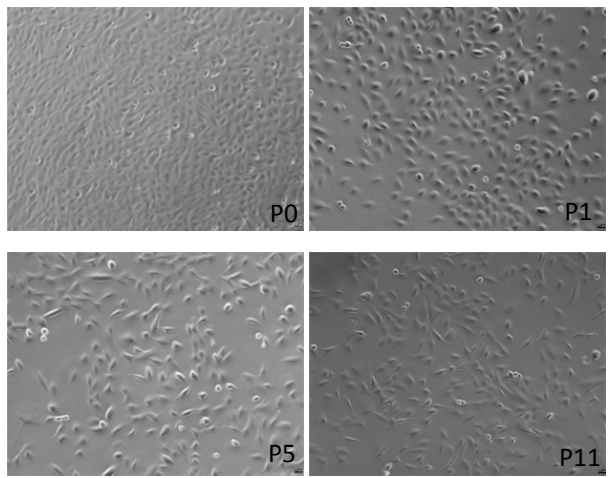

Figure 1. Morphology of USC: Phase contrast microscopic appearances of urine derived stem cell clones showing "rice-grain" like morphology.
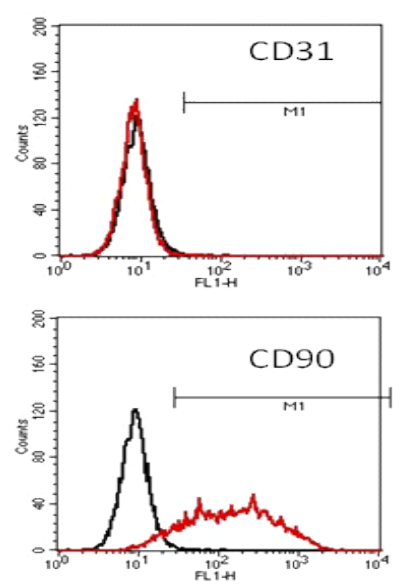
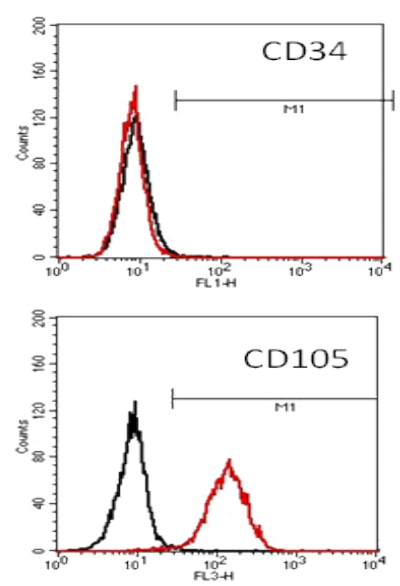
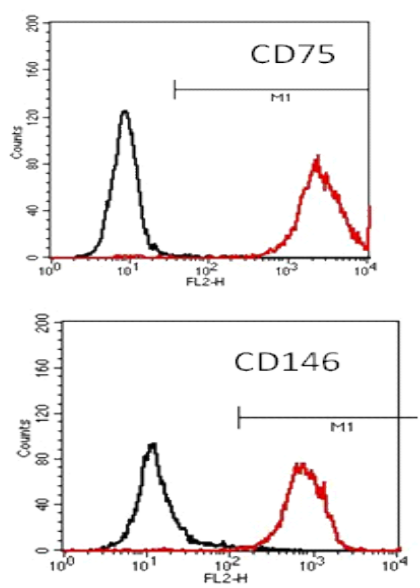

Figure 2. Stem cell surface marker of USC cell clones. 


\section{Myogenic differentiation of USCs}

Our previous studies demonstrated that USCs can be efficiently induced to differentiate into smooth muscle cells $[23,24]$. After myogenic differentiation with TGF-1 $(2.5 \mathrm{ng} / \mathrm{ml})$ and PDGFBB $(5.0 \mathrm{ng} / \mathrm{ml})$, induced USCs displayed spindle-shape morphology, and expressed smooth muscle-specific gene and protein markers (such as smoothelin, myosin, and desmin). In addition, these cells exhibited a contractile pattern similar to bladder smooth muscle cells. In our recent study, we demonstrated that USCs can give rise to skeletal muscle-like cells with myotube formation in standard myogenic differentiation media (i.e. SkGM2/Differentiation Medium. USCs are culture in Sk-MC growth Medium (SkGM-2, Lonza) for 2 weeks followed by Differentiation medium (DMEM:F-12 [1:1], 2\% Horse serum and 1\% Penecillin/streptomycin). Differentiated USCs expressed specific skeletal muscle cell transcripts and protein markers (myoD, myogenin, myosin, and Myf5). In vitro calcium labeling studies showed that skeletal myogenic differentiated USCs resulted in increased calcium efflux. After the induced cells $\left(1 \times 10^{6}\right)$ mixed with $2 \%$ collagen-I gel $(100 \mu \mathrm{l})$ were implanted into the tibialis anterior muscle of nude mice for one month, the grafted cells maintained expression of skeletal muscle cell markers in vivo. The USCs differentiated into a skeletal muscle cell lineage, which could be used as a potential source for cell injection therapy in the treatment of urethral sphincter dysfunction.

\section{Paracrine factors of USCs}

We have recently demonstrated that USCs are able to secrete several angiogenic growth factors, such as VGEF, PDGF, FGF-1, IGFBP-1 and 3, MMP-9, and angiogenin when UCSs in culture media were assessed by ELISA. In vivo studies showed that USC s can stimulate the resident cells to migrate from the host into the graft tissue. More cells with no human nuclear protein expression were observed in the sites where USCs were implanted, compared to a cellfree injection sites.

There are several potential advantages to using USCs as a cell source for cell therapy, including the following: 1) USCs can be easily harvested by a non invasive method and grown in culture; 2) they do not require enzyme digestion or culture on a layer of feeder cells to support cell growth; 3) they start as one single-cell colony in the initial culture, which creates more homogeneous cells after differentiation; 4) since they possess telomerase activity, they can generate more cells and provide a longer life span for tissue regeneration; 5) they possess higher plasticity and more efficiency when induced to differentiate into other functional cells, including endothelial and muscle cells; and 6) as autologous cells, USCs do not raise ethical issues or cause immune reactions to engineered implants. Therefore, obtaining and using stem cells from urine could be an attractive alternative to the standard urological tissue biopsies currently used in cell therapy and tissue engineering. Additionally, myogenic differentiated USCs might be used in other diseases involved in sphincter dysfunction via an endoscopic procedure, including muscle sphincter-deficient diseases such as vesicoureteral reflux, gastroesophageal reflux disease [25,26], and anal incontinence [27]. 


\section{Conclusions}

USCs as pericytes/mesenchymal stem cells could be easily obtained by a non invasive approach. These cells are able to extensively expand and can be induced to differentiate efficiently into a skeletal myogenic cell lineage. In addition, myogenically-differentiated USCs expressed skeletal muscle cell gene and protein markers. Moreover, USCs are able to recruit resident cells from the host to participate in tissue regeneration by their secretion of paracrine factors. Use of autologous USCs may serve as a more convenient and low-cost cell source comparable in quality to other types of adult stem cells, and could generate a large number of cells in vitro for potential use in treatment of patients with SUI or other diseases due to sphincter deficiency.

\section{Author details}

Yingai Shi ${ }^{1}$, YuLin $\mathrm{Li}^{1}$, JinYu Liu ${ }^{1}$ and Yuanyuan Zhang ${ }^{2 *}$

*Address all correspondence to:yzhang@wakehealth.edu

1 Key Laboratory of Pathobiology, Ministry of Education, Jilin University, Changchun, China

2 Wake Forest Institute for Regenerative Medicine, Winston-Salem, NC, USA

\section{References}

[1] Voelker, R. (1998). International Group Seeks to Dispel Incontinence "Taboo". JAMA, 280(11), 951-953.

[2] Hampel, C W. D, Benken, N, Eggersmann, C, \& Thuroff, J. W. (1997). Definition of overactive bladder and epidemiology of urinary incontinence. Urology 50 (4-14).

[3] Abrams, P, Cardozo, L, Fall, M, Griffiths, D, Rosier, P, Ulmsten, U, Van Kerrebroeck, P, Victor, A, \& Wein, A. (2002). The standardisation of terminology of lower urinary tract function: Report from the standardisation sub-committee of the International Continence Society. Neurourology and Urodynamics 21(2), 167-178.

[4] Catalona, W. J, Ramos, C. G, \& Carvalhal, G. F. (1999). Contemporary results of anatomic radical prostatectomy. CA Cancer J Clin 49(5), 282-296.

[5] Wagner, T. H, \& Hu, T. W. (1998). Economic costs of urinary incontinence in 1995. Urology 51(3), 355-361.

[6] Macura, K. J, \& Genadry, R. R. (2008). Female urinary incontinence: pathophysiology, methods of evaluation and role of MR imaging. Abdom Imaging 33(3), 371-380. 
[7] Delancey, J. O. (2010). Why do women have stress urinary incontinence? Neurourol Urodyn 29 Suppl 1(S, 13-17.

[8] Shamliyan, T. A, Kane, R. L, Wyman, J, \& Wilt, T. J. (2008). Systematic review: randomized, controlled trials of nonsurgical treatments for urinary incontinence in women. Ann Intern Med 148(6), 459-473.

[9] Kerr, L. A. (2005). Bulking agents in the treatment of stress urinary incontinence: history, outcomes, patient populations, and reimbursement profile. Rev Urol 7 Suppl 1(SS11., 3.

[10] Xu, Y. M, Zhang, X. R, Sa, Y. L, Chen, R, \& Fei, X. F. (2007). Bulbourethral composite suspension for treatment of male-acquired urinary incontinence. Eur Urol 51discussion 1715-1706.(6), 1709-1714.

[11] Hinoul, P, Roovers, J. P, Ombelet, W, \& Vanspauwen, R. (2009). Surgical management of urinary stress incontinence in women: a historical and clinical overview. Eur J Obstet Gynecol Reprod Biol 145(2), 219-225.

[12] Smaldone, M. C, Chen, M. L, \& Chancellor, M. B. (2009). Stem cell therapy for urethral sphincter regeneration. Minerva Urol Nefrol 61(1), 27-40.

[13] Kinebuchi, Y, Aizawa, N, Imamura, T, Ishizuka, O, Igawa, Y, \& Nishizawa, O. (2010). Autologous bone-marrow-derived mesenchymal stem cell transplantation into injured rat urethral sphincter. Int J Urol 17(4), 359-368.

[14] Drost, A. C, Weng, S, Feil, G, Schäfer, J, Baumann, S, Kanz, L, Sievert, K. D, Stenzl, A, \& Möhle, R. (2009). In vitro myogenic differentiation of human bone marrow-derived mesenchymal stem cells as a potential treatment for urethral sphincter muscle repair. Ann NY Acad Sci 1176(1), 135-143.

[15] Dezawa, M, Ishikawa, H, Itokazu, Y, Yoshihara, T, Hoshino, M, Takeda, S-i, Ide, C, \& Nabeshima, Y-i. (2005). Bone marrow stromal cells generate nuscle cells and repair muscle degeneration. Science 309(5732), 314-317.

[16] Kocaefe, C, Balci, D, Hayta, B. B, \& Can, A. (2010). Reprogramming of human umbilical cord stromal mesenchymal stem cells for myogenic differentiation and muscle repair. Stem Cell Rev 6(4), 512-522.

[17] Lin, G, Wang, G, Banie, L, Ning, H, Shindel, A. W, Fandel, T. M, Lue, T. F, \& Lin, C. S. (2010). Treatment of stress urinary incontinence with adipose tissue-derived stem cells. Cytotherapy 12(1), 88-95.

[18] Mizuno, Y, Chang, H, Umeda, K, Niwa, A, Iwasa, T, Awaya, T, Fukada, S, Yamamoto, H, Yamanaka, S, Nakahata, T, \& Heike, T. (2010). Generation of skeletal muscle stem/progenitor cells from murine induced pluripotent stem cells. FASEB J 24(7), 2245-2253. 
[19] Lin, C. S, \& Lue, T. F. (2012). Stem cell therapy for stress urinary incontinence: a critical review. Stem Cells Dev 21(6), 834-843.

[20] Ko, I. K, Ju, Y. M, Chen, T, Atala, A, Yoo, J. J, \& Lee, S. J. (2012). Combined systemic and local delivery of stem cell inducing/recruiting factors for in situ tissue regeneration. FASEB J 26(1), 158-168.

[21] Zhang, Y, Mcneill, E, Tian, H, Soker, S, Andersson, K. E, Yoo, J. J, \& Atala, A. (2008). Urine derived cells are a potential source for urological tissue reconstruction. J Urol 180(5), 2226-2233.

[22] Bodin, A, Bharadwaj, S, Wu, S, Gatenholm, P, Atala, A, \& Zhang, Y. (2010). Tissueengineered conduit using urine-derived stem cells seeded bacterial cellulose polymer in urinary reconstruction and diversion. Biomaterials 31(34), 8889-8901.

[23] Bharadwaj, S, Liu, G, Shi, Y, Markert, C, Andersson, K. E, Atala, A, \& Zhang, Y. (2011). Characterization of urine-derived stem cells obtained from upper urinary tract for use in cell-based urological tissue engineering. Tissue Eng Part A 17(15-16): 2123-2132.

[24] Bharadwaj, S W. S, Rohozinski, J, Furth, M, Lan, X, \& Atala, A. (2010). Multipotential differentiation of human urine-derived stem cells. J Urol 183.e61.

[25] Fascetti-leon, F, Malerba, A, Boldrin, L, Leone, E, Betalli, P, Pasut, A, Zanon, G. F, Gamba, P. G, Vitiello, L, \& De Coppi, P. (2007). Murine muscle precursor cells survived and integrated in a cryoinjured gastroesophageal junction. J Surg Res 143(2), 253-259.

[26] Ganz, R. A, Fallon, E, Wittchow, T, \& Klein, D. (2009). A new injectable agent for the treatment of GERD: results of the Durasphere pilot trial. Gastrointest Endosc 69(2), 318-323.

[27] Frudinger, A, Kolle, D, Schwaiger, W, Pfeifer, J, Paede, J, \& Halligan, S. (2010). Muscle-derived cell injection to treat anal incontinence due to obstetric trauma: pilot study with 1 year follow-up. Gut 59(1), 55-61. 
